\title{
O DIREITO VISIGÓTICO
}

\author{
Luiz Carlos de Azevedo \\ Professor Associado de Direito Civil da Faculdade de Direito da \\ Universidade de São Paulo
}

\begin{abstract}
Resumo:
O autor aborda, neste trabalho sobre a queda do Império Romano, as fontes do Direito germânico, os concílios visigóticos e o Código Visigótico, incluindo a sua permanência após a invasão muçulmana.

Abstract:

The author approaches, in this work, on the fall of the Roman Empire, the sources of the germanic Right, council and the Visigothic Code, including its permanence after the Muslim invasion.
\end{abstract}

Unitermos: Direito germânico, concílios visigóticos, Código Visigótico.

Sumário:

1. A queda do Império Romano do Ocidente. Os visigodos. O Direito germânico e as suas instituições;

2. Fontes do Direito germânico. As compilações de leis do reino visigótico: Código de Eurico. Edictum Theodorici. Lex Romana Visigothorum;

3. Os concílios visigóticos;

4. O Código Visigótico ou "Fuero Juzgo";

5. A permanência do Código Visigótico após a invasão muçulmana.

1. A enorme extensão do Império Romano acabaria por levá-lo à desintegração e aniquilamento. Abrangendo limites que chegavam aos confins do mundo antigo; mas, perdido, por outro lado, na retaliação constante de uma insegura minoria dirigente, onde se digladiavam interesses nem sempre claros de senadores ambiciosos e rudes oficiais, os quais, malcolocados no poder, viam-se derribados pelas falanges contrárias, tornou-se impossível resguardar as fronteiras diante das vagas dos povos germânicos que os ventos orientais vinham impelindo. 
Desde Tácito temiam-se as investidas dos povos que habitavam as estepes do Don e Dniester e as margens do Rio Danúbio, pois este, na verdade, segundo o historiador, sustentava-se como débil obstáculo a quem realmente pretendesse atravessálo, (Germânia, XXVIII).

No final do século IV, provindos da Ásia, os hunos se arrojam pela Europa Central, levando seus contingentes, e mais, os godos, que não lhes podem resistir, a se precipitar sobre o decadente Império, a esta altura já enfraquecido pela divisão em dois governos distintos, do Oriente e do Ocidente, (395 D.C.).

Acompanhando as invasões, os visigodos situam-se, primeiro, pelo norte da península itálica, e com Alarico chegam a saquear Roma; depois, estarão na Aquitânia, na antiga província senatorial narbonense, cruzam os Pirineus e penetram na Hispania, até conquistá-la praticamente por completo, quando dominam os remanescentes romanos, suevos, alanos, vândalos, expulsando, também, o Exército de Belisário.

A capital do reino é agora Toledo e a monarquia tem caráter eletivo, motivo das contínuas dissensões entre os aspirantes ao trono, quando de sua vacância.

Carrega o povo visigodo toda a tradição de ascendência germânica, que em nada se assemelha ao grau de civilização das instituições romanas, as quais constituíam a marca e o orgulho da "urbs" imperial.

Não-obstante, a despeito da aspereza do trato na condução de seu agir, resultado da própria luta por uma sobrevivência árdua e espinhosa, tinham os visigodos, como característica comum destes povos germânicos, um sentimento arraigado pelos costumes, que bem conservavam, e qué de pai para filho faziam empenho em transmitir.

A idéia de preservação da paz ("fridr") da familia, (sippe) a qual compreendia tanto a parentes de sangue, quanto aos descendentes em linha masculina de um tronco paterno comum, encontrava-se ínsita na consciência de cada um, como sempre ocorrera, desde tempos mais remotos, entre os integrantes do mesmo clã.

Por isto, embora individualistas, por natureza, traziam impregnado em suas consciências este sentimento coletivo e igualitário de proteção do grupo, para que não se perdesse o propósito maior, de manutenção da paz; violá-la - acreditavam -, seria atentar contra os interesses da "sippe", seria incidir na mais grave falta conhecida nas primitivas instituições germânicas, seria receber, por conseqüência, a repressão mais severa, equivalente à pena capital: o culpado era banido da comunidade.

Reuniam-se em assembléias, sendo ainda Tácito quem descreve alguns de seus trâmites, causando-lhe espécie a severidade do ritual simbólico e formalista, que então se estabelecia: o chefe tomava a palavra e, ao ouví-lo, a turba, se a notícia os 
desagradava, repeliam-na com murmúrios de reprovação; mas, se aprovada, agitavam as lanças, chocando-as entre si; "honoratissinum assensus genus est armis laudare" o sufrágio pelas armas era o sinal mais honorável deste assentimento, (Germânia, XI). Tudo se fazia oralmente, sob a tônica do princípio acusatório, e, não-raro, a parte que se sentia lesada lançava o repto perante os demais, reclamando desagravo. Outras vezes, porém, sentindo a ausência ou debilidade do poder público, ou desprezando, por hábito, o auxílio de terceiro para a solução de pendência que a tinha por só sua, o membro do clã partia para a retorção contra o desafeto, considerando legítimo o emprego da "vis privata" No entanto, esta era por princípio coibida, pois a ninguém interessava o enfraquecimento da tribu; por isto, buscava-se evitar retaliações ou vinganças entre os clãs, sendo comum, nessa contingência, o recurso ao "wergeld" por meio do qual o ofensor pagava ao ofendido uma multa ou compensação pecuniária, representada por um bem material ou dinheiro, (de "wir" homem, e gold" ouro, o preço do homem ou do prejuízo ocorrido).

Outra solução seria aceitar a sorte e o apoio na Justiça divina, partindo os contendores para o duelo judiciário, sob a vista do chefe da comunidade; e na colheita das provas, utilizavam-se das ordálias ou juízos de Deus, sendo um dos exemplos desta prática mergulhar as mãos do acusado em água fervente para saber se era culpado ou inocente.

Estas formas rudimentares de proceder, todavia, conlecerão modificações, quando do contato dos invasores com os despojos do extinto Império do Ocidente, pois, desde logo, os chefes dos clãs sentiram a necessidade de aproveitar o espólio cultural de Roma, em especial o acervo representado por seu notável ordenamento jurídico.

E, desde o momento em que se admitiu tal receptividade, sucedem-se as "leges barbarorum" ou leis populares, onde o antigo Direito consuetudinário, que continuou presente, passa a receber o influxo dos preceitos extraídos ao Direito Romano.

E havia uma forte razão para que os reis e condutores destes povos não se sentissem infensos àquelas normas, posto que estranhas lhes parecessem; pois serviam bem melhor a lhes assegurar o poder, já que provindas de um sistema no qual se fazia empenho em tornar absoluta a autoridade do soberano, característica marcante do dominato no caminho para a construção do Direito justinianeu.

2. Fundado exclusivamente no costume, o Direito germânico mais antigo não trazia leis ou documentos escritos e qualquer reconstrução a esse respeito, esbarra na falibilidade, já que nas inscrições rupestres encontradas pode ter ocorrido a influência 
do Direito Romano, ao tempo em que o Império gozava desta hegemonia, de modo a alterar o sentido original das disposições porventura ali transcritas.

Assim, as fontes se situam mais nas descrições relatadas pelos autores romanos, como César, Tácito, Dione, Cássio e outros; nas lendas provenientes da exuberante mitologia germânica, e, principalmente, neste período de contato, na legislação que foi sendo gradativamente editada e que trazia o nome dos povos que a seguiam e respeitavam: lei dos francos, (pactus legis salicae) dos burgùndios, ripuários, etc.; e, entre estas, as leis dos visigodos.

Neste último reino, ao lado do direito vulgar, que permanece, "não apenas como direito positivo para disciplinar as relações juridicas do povo vencido, mas também como modelo a inspirar as próprias leis estabelecidas pelos vencedores, em razão da influência que a civilização romana exerceu sobre aquele povo germânico" (Moacyr Lobo da Costa, A revogação da sentença, p. 85), sucedem-se as compilações, datando a primeira, ao que consta, dos anos 476 da Era Cristã, o denominado "Código de Eurico" onde se encontram reunidos, nos fragmentos que se localizaram, tanto normas de Direito Romano, quanto costumes de ascendência germânica.

Antes desta, porém, discute-se a origem de um outro diploma, o "Edictum Theodorici" atribuido ao rei ostrogodo desse nome, mas que teria sido baixado por Teodorico II, monarca visigótico que reinou ainda na Gália, entre 453 e 466; também esta coletânea reproduz textos romanos do período, como o Código Teodosiano e aqueles que o antecedem, o Gregoriano e o Hermogeniano.

A seguir, vem a "Lex Romana Visigothorum", ou Breviário de Alarico, que data de 506: trata-se de importante compilação, que traz tanto o "jus" quanto as "leges" isto é, o conteúdo doutrinário e as constituições imperiais. Parece que este rei, segundo pelo nome, pretendeu acompanhar o mesmo espírito que inspirara os compiladores do Código Teodosiano, dirimindo os inevitáveis desencontros surgidos em decorrência da grande quantidade de leis extravagantes, muitas delas já anacrônicas. Esta medida tinha ainda mais razão de ser no reino visigodo, onde habitavam povos de diferente origem, religião e costumes. Por isso, Alarico teria buscado apaziguar ânimos e querelas ocorrentes entre as duas raças, dirigindo o seu "comonitoritum" a godos e hispano-romanos, tanto que o edito conclama o "universi populi nostri". Compõe-se o Breviário de várias constituições extraidas do Código Teodosiano, outras tantas novelas de imperadores romanos, um resumo das "Institutas" de Gaio, as sentenças de Paulo e outros excertos de jurisprudência.

3. Com Recaredo, convertem-se os visigodos ao catolicismo (589) e, a 
partir de então, os concílios passam a ter grande importância na estrutura política do reino, porque, além dos assuntos eclesiásticos, discutia-se nessas assembléias matéria de natureza administrativa, econômica e civil. Delas participavam os altos dignatários eclesiásticos, representantes das sedes episcopais juntamente com o monarca, nobres e membros do palatinado, da Corte visigótica. Nas reuniões deste órgão legislativo ditavam-se normas e cânones, ocorrendo singular fusão entre o Direito secular e o Canônico, a qual iria servir de fonte ao futuro Código Visigótico.

Para que se tenha idéia da transcendência das questões ali levantadas, oportuno lembrar o cânone II, do XIII Concílio de Toledo (683), que estabeleceu o chamado "habeas corpus" visigótico; dizia ele que nenhuma pessoa vinculada ao rei por juramento de fidelidade, exceto em caso de culpa evidente, poderia ser presa, acorrentada, desapossada de seus bens, torturada para que se arrancasse por força a confissão, antes de ser apresentada à assembléia, conservando, até o julgamento, seus direitos e prerrogativas; e às pessoas livres, posto que de condição inferior, guardavase igual procedimento.

Em outro concílio, bem anterior (638) decretou-se, também, que os inocentes não podiam ter sua vida atingida pela malícia dos acusadores, de tal modo que ninguém seria acusado por outro, ou seria supliciado, sem que o acusador se apresentasse, cumprindo-se, a seguir, as normas e cânones em relação às matérias que se aplicassem, (Concílio de Toledo VI, can. XI).

4. Sob a coroa de Rescesvindo (654), promulga-se o chamado "Código Visigótico" ou "Fuero Juzgo", a mais importante compilação de leis dos visigodos, a qual reúne tanto os antigos costumes germânicos, quanto as disposições oriundas do Direito Romano e Canônico. Destes, normas insertas na Lex Romana Visigothorum e no que trazia de romano o Coder Euriciano; além disto, os cânones dos concílios e os ensinamentos de Isidoro de Sevilha.

Os doze livros que a compõem, trazem leis com a nota "antiqua" ou "antiqua noviter emendata", referindo-se, também, ao rei que as editou, entre estas, as revistas por Leovigildo e Chindasvindo, anos atrás. O Código Visigótico traz duas versões: uma, em latim, de 654 , e outra, em castelhano, que dataria do reinado de D. Fernando, já no século XIII.

O Título I trata da eleição dos príncipes e da forma como devem eles reinar; originar-se-ia do quarto concílio de Toledo, realizado em 633, (era de 671) Sisenando reinante, que se designava "regis Hispaniae atque Galliae". O primeiro livro dispõe como devem ser feitas as leis: non deve fazer ley em contienda, mas ponerla 
ondradamiente", ou seja, há de ser bem ordenada, compreensível, para que todos a entendam, (Liv, I, Tít, I, n. II). Em suma, a lei deve ser manifesta e clara, de modo que o juízo que dela se extrair, se faça de modo lhano e aberto. Há de ser guardada, segundo o costume da cidade e ser conveniente, proveitosa e necessária à época e lugar aos quais se aplica, (Liv. I, Tít. I, n. VI; Liv. I, Tít. II, n. IV). Marca do respeito aos costumes, diz a lei, a certa altura, que é melhor emendar a lei do que alterá-los, (Liv. I, Tít. I, n. IX).

Por sua vez, o juiz, no seu ofício, deve ser pronto e ágil, ao indagar; (indagando vivax) firme, ao prevenir; (preeveniendo fixus) não se mostrar ansioso, para decidir; (decernendo non anxius) castigar com moderação, (percutiendo parcus) e perdoar, com freqüiência (parcendo assiduos), (Liv. I, Tít. I, Lei VII, versão latina).

O Livro II estende-se sobre os processos e causas; o terceiro e o quarto, sobre o casamento e Direito sucessório; o quinto, dos contratos e assuntos correlatos; do sexto ao nono, do Direito Penal, ali se inscrevendo sanções de extrema severidade, que chocam e causam repulsa nos dias de hoje, mas que não eram próprias dos visigodos, repetindo-se em outros corpos legislativos do período: morte e execução sob suplício, mão ou nariz cortados, castração, açoites, etc. Os tempos eram rudes e as sanções desapiedadas contrastavam com as prescrições do Livro Primeiro. Diferentes influências, resultados da mesma forma distintos.

Completava-se a legislação com normas sobre terras, arrendamentos, disposições, acerca dos físicos e de suas responsabilidades, mercadores e marinheiros; e, também, dos hereges e judeus.

A partir daí, "que nengun omne non aya otro Libro sino que este". diz o rei (Liv. II, Tít. I, n. IX), impondo multa que se aplicava às partes e aos juízes que não queimassem os compêndios que contivessem as leis revogadas. A intenção era fazer cessar de vez a diversidade legislativa, tanto que "la muier romana puede casar com el omne godo é que la muier goda puede casar com el omne romano. (Liv. III, Tít. I, del ordenamiento de las bodas")

A ninguém, por outro lado, era lícito ignorar a lei, "quod nulli leges nescire liceat", (Liv. II, Tít. I, n. III), Isto porque, continua o texto, na versão castelhana: "ca el que mal fiziere, non deve seer sin pena, maguer (ainda) que diga, que non sabie las leyes ni el derecho"

Esta ordem, ainda que correta em seus propósitos, trazia muito de hipotético, a considerar as pessoas para as quais se dirigia; árdua era a vida, as comunicações dificeis, muitos poucos sabiam ler e escrever, mesmo entre os membros 
da nobreza; é de acreditar, assim, vigorasse o código, em maior amplitude, junto aos mais cultos e abonados, próximos ao rei e sua Corte, na capital e nas cidades mais prósperas; quanto ao povo, bem como aqueles que residiam nas aldeias, faziam-se reger pelos costumes, prática que se prolongaria no tempo, segundo mostram as coleções de "utsages" e "fueros" medievais.

Um exemplo desta situação encontra-se no Livro V, Tít. VI, n. I, quando ali se diz que "defendemos à tod omne que non prende por si. E si el omne que es libre prenda por si mismo por fuerza à otri, pague el duplo del penno. E si el que prenda es siervo, peche el penno, é demás reciba C azotes"

Cumprir-se-ia realmente a lei? Qual ạ distância que medeava entre o comando, oriundo de quem se intitulava "Don Flavio Rescindo, rey de Dios" nos moldes dos imperadores romanos, e que incorporara esta lei "antigua" ao capítulo, e o agir de seus súditos? Pois estes não se despojariam facilmente dos velhos hábitos, entre os quais aquele que admitia a penhora pelas próprias mãos por quem se sentira atingido em seu direito, face a relutância ou inércia do devedor.

Tudo leva a crer, então, que até onde chegava o poder real, obedeciase a legislação, na maneira como vinha disposta, pois a severidade das sanções resultantes de seu descumprimento impedia ou reduzia a idéia de confronto; mas esta autoridade, presente no fausto do palácio, debilitava-se na medida em que o rei e seus delegados se encontravam cada vez mais distantes dos povoados, onde vigorava a prática costumeira, secularmente observada; não será por outro motivo, aliás, que bem mais tarde, os reis cristãos da reconquista aos árabes terão por hábito deambular pelos seus domínios, buscando manter presente e atuante seu poderio, ocasião em que, a par das medidas administrativas e econômicas, que tomavam, estavam também distribuindo Justiça e levando a paz do soberano aos termos porventura conturbados.

5. Tão-poderosos se criam os reis visigodos que jamais poderiam atinar estivessem à beira do perdimento; tudo lhes minava à volta, desde o abandono da simplicidade, que lhes fora símbolo, até as dissensões periódicas internas, surgidas a cada sucessão ao trono; que dizer, então, das outras raças, fosse do povo hebreu, que perseguiam, fosse do muçulmano, que desprezavam?

Malsabiam que estes últimos iriam desmanchar, em Guadalete, (711) tão-ilusória potestade, reduzindo os vencidos às montanhas das Astúrias.

Não contaria, o Código Visigótico, entretanto, tão-só com estes parcos sessenta anos de vigência; malgrado a invasão, por força de circunstâncias várias, entre elas a de não desejarem os sarracenos maior contato com cristãos, infiéis a Mafoma, 
continuaram estes a utilizar-se das leis que lhes eram próprias, fazendo-o, todavia, à custa de largo preço.

Assim, não-obstante carregados de tributos, "pagos por cabeça ou por mês" lograram os cristãos alcançar "proteção e perfeita tolerância civil e religiosa" (Coelho da Rocha, M. A., "Ensaio sobre a História do Governo e da legislação) em Portugal" p. 36).

O "Liber judiciorum" continuará, desta forma, a vigorar junto ao povo conquistado, mesmo porque o ânimo dos vencidos, por não aceitar a derrota desde o momento em que esta ocorreu, passará a dar ensejo à obstinada e paulatina reconquista.

Anexo 1

De Los Libros Y Títulos Que Contiene El Fuero Juzgo.

\section{Primer Título.}

De la elección de los príncipes et del insinnamiento como deben iudgar derecho et de la pena de aquellos que iudgan torto.

\begin{tabular}{|c|c|}
\hline $\begin{array}{c}\text { Libro I. } \\
\text { Del facedor de la ley et de las leyes. }\end{array}$ & $\begin{array}{c}\text { Libro VII. } \\
\text { Libro II. } \\
\text { De los furtos é de los engannos. }\end{array}$ \\
\hline $\begin{array}{c}\text { Libro III. } \\
\text { Libro VIII. }\end{array}$ & $\begin{array}{c}\text { De las fuerzas é de los damnos é de los } \\
\text { quebrantamientos. }\end{array}$ \\
\hline $\begin{array}{c}\text { De los casamientos é de las } \\
\text { nascencias. }\end{array}$ & $\begin{array}{c}\text { Libro IX. } \\
\text { De los siervos foidos é de los que } \\
\text { tornan. }\end{array}$ \\
\hline $\begin{array}{c}\text { Libro IV. } \\
\text { Del linage natural. }\end{array}$ & $\begin{array}{c}\text { Libro X. } \\
\text { De las particiones é de los tiempos é de } \\
\text { los annos é de las lindes. }\end{array}$ \\
\hline $\begin{array}{c}\text { Libro V. } \\
\text { De las avenencias é de las } \\
\text { compras. }\end{array}$ & $\begin{array}{c}\text { Libro XI. } \\
\text { Libro VI. }\end{array}$ \\
\hline $\begin{array}{c}\text { Les fisicos é de los mercadores de } \\
\text { de los tormentos. }\end{array}$ & $\begin{array}{c}\text { De devedar los tuertos é derraigar las marineros. } \\
\text { sectas é sus dichos. }\end{array}$ \\
\hline
\end{tabular}


Anexo 2

Concílio De Toledo VI: a. 638

\section{Concílio VI de Toledo, de cuarenta y ocho obispos}

Reunidos nosotros, los obispos de las Españas y de las Galias, por las provechosas exhortaciones del sumo, ortodoxo y gloriosísimo rey Chintila, y ocupando los paestos correspondientes en el pretorio de Toledo, en la iglesia de santa Leocadia, mártir, el día 9 de enero, año segundo del arriba indicado rey y triunfador en Cristo, era 676, ante todo establecimos este decreto acerca de la fe.

XI. Que no se condene a nadie sin acusador legal.

Es justo que la vida de los inocentes no sea manchada por la malicia de los acusadores, y por lo tanto nadie que esté acusado por otro será entregado al suplicio hasta que el acusador se presente y se examinen las normas de las leyes y de los cánones, y si se prueba que es persona incapaz para acusar, no se admita la acusación, a no ser que se trate de crimen de lesa majestad.

\section{'Item Concilium Toletanum Vi, XIviii Episcoporum [Universale] Habitum [In Nomine Domini Nostri Iesu Christii Feleciter|}

Convenientibus nobis Spaniarum Galliarumque pontificibus summi orthodoxi et gloriosissimi Chintilani regis salutaribus hortamentis, atque in praetorio Toletano in ecclesiam sanctae Leocadiae martyris debitis sedibus conlocatis, sub die quinto idus ianuarias anno praefati principis et triumfatoris in Christo secundo, era sexcentesima septuagesima sexta, hoc decretum fidei prius sancimus.

$\mathrm{XI}$. Ne sine accusalore legitimo quispiam condemnetu:

Dignum est ut vita innocentum non maculetur pernicie accusantum: ideo quisquis a quolibet criminatur non antea accusatus supplicio dedicetur, quam accusator praesentetur, atque legum et canonum sententiae exquirantur, ut si indigna ad causandum persona invenitur, ad eius accusationem non iudicetur, nisi ubi pro capite regiae maiestatis causa versatur. 
Anexo 3

Concílio De Toledo XIII: a. 683

En el nombre del Señor, actas sinodales del Concilio Toledano XIII, era 721, en el año cuarto del reinado del excelentísimo príncipe Ervigio.

II. Por lo cual, tomando una medida conforme a los deseos del rey, decretamos en común, que ninguno en adelante del orden palatino, o de los pertenecientes a la santa religión, por estratagema ardida por el rey, o por instigación de otra potestad seglar, o con el apoyo de la maliciosa voluntad de cualquier otro hombre, sea privado del honor de su grado o de servir en el palacio real, fuera del caso de manifiesto y evidente indicio de su culpa, y no se le aprisione, ni encadene, ni se le someta a tormento, ni se le castigue con cualquier clase de penas corporales o azotes, ni se le prive de sus bienes, ni sea encerrado en prisión, ni se le rapte, valiéndose aquí y allá de injustas ocasiones, con lo cual se le arranque una confesión por la fuerza, oculta o fraudulenta, sino que aquel que es acusado, conservando las prerrogativas de su categoría, y sin sufrir antes los perjuicios reseñados más arriba, será presentado en la pública deliberación de los obispos, de los grandes y de los gardingos, e interrogado con toda justicia y si fuere culpable del

\section{In nomine domini incipiunt gesta} synodalia habita in urbe toletana sub era $\mathrm{DCC} \mathrm{XXI}^{\mathrm{a}}$ anno regni excellentissimi Ervigii principis quarto

II. Un de congruam devotioni eius sententiam decernentes hoc in commune decrevimus ut nullus deinceps ex palatini" ordinis gradu vel religionis sanctae conventum, regiae subtilitatis astu vel profanae potestatis instineta sive quorumbilet hominum malitiosae volumptatis obnisu citra manifestum et evidens culpae suae indicium ab honore sui ordinis vel servitio, domus regiae arceatur, non ante vinculorum nexibus inligetur, non quaestioni subdatur, non quibuslibet tormentorum vel flagellorum generibus maceretur, non vebus privetur, non etiam carceralibus custodiis mancipetur, neque adhibitis hinc inde iniustis occasionibus abdicetur, per quod illi violenta, oculta vel fraudulenta professio extrahatur: sed is qui accusatur gradum sui ordinis tenens et nicil ante de supradictorum capitulorum nocibilitate persentiens, in publica sacerdotum seniorum atque etiam gardingorum discussione deductus [et iustissime perquisitus] aut abnoxius reatui detectae culpae legum poenas excipiat, aut innoxius iudicio omarium 
delito, sufra las penas que las leyes señalan para el cuimen que se de ha descobierto, y si fuere inocente, sea declarado tal por el juicio de todos.

También de las restantes personas libres que no ocuparon cargos en palacio, y sin embargo parecen poseer la dignidad de libres, conviene guardar el mismo orden, las cuales, aunque como suele suceder sean azotadas por el príncipe por algunas culpas pequeñas, sin embargo no perderán por esto el derecho de testificar, ni serán privadas de las cosas que se les deben. conprobatus appareat.

Conprobatum. Nam et de ceterorum ingenuorum personis, qui palatinis officiis non haeserunt et tamen ingenuae" dignitatis titulum reportare videntur, similis ordo servabitur, qui etiamsi pro culpis minimis, ut adsolet, flagellorum ictibus a principe verberentur, pon tamen ex hoc aut testimonium amissuri sunt aut rebus sibi debitis privabuntur.

'.("Concílios visigóticos e hispano-romanos" Edición preparada por José Vives, Barcelona, Madrid, MCMLXIII). 
Anexo 4

\begin{tabular}{|ll|}
\hline \multicolumn{2}{|c|}{ Monarquia } \\
& \\
& Visigoda \\
Ataulfo & \\
Sigerico & $414-415$ \\
Walia & 415 \\
Teodoredo & $415-418$ \\
Turismundo & $418-451$ \\
Teodorico & $451-453$ \\
Eurico & $453-466$ \\
Alarico II & $466-484$ \\
Gesaleico & $484-507$ \\
Amalarico & $507-511$ \\
Teudis & $511-531$ \\
Teudiselo & $531-548$ \\
Agila & $548-554$ \\
Atanagildo & $548-554$ \\
Liuva I & $554-567$ \\
Leovigildo & $568-573$ \\
Recaredo I & $573-586$ \\
Liuva II & $586-601$ \\
Witerico & $601-603$ \\
Gundemaro & $603-610$ \\
Sisebuto & $610-612$ \\
Recaredo II & $612-621$ \\
Suintila & 621 \\
Sisenando & $621-631$ \\
Chintila & $631-636$ \\
Tulga & $636-639$ \\
Chindasvindo & $639-642$ \\
Recesvinto & $642-640-702$ \\
Wamba & $649-672$ \\
Ervigio & $672-680$ \\
Egica & \\
Witiza & \\
Akila & \\
Rodrigo & \\
\hline
\end{tabular}

São Paulo, junho de 2001 
Fontes e Textos Legais

BARBARORUM LEGES ANTIQUAE, F. Paulus Canciani, Venetiis, apud Sebastianum colectium et Franciscum Pitteriu, 1.781, v. I (qui continentur Edicta Regum Ostro - gothorum, Leges Langobardicae: Rotharis Leges, Liutprandi Legum, Caroli Magni Leges, Ludovici Pii Augusti Leges); 1783, vol. II (qui continentur Pactus Legis Salicae, Lex Ripuariorum, Lex Baiuvariorum).

LA GERMANIE, Tacite, Paris, Garnier, 1949.

EDICTUM THEODERICI REGIS ITALIAE, Pier Luigi Falaschi, Milano, A. Giuffré, 1966.

EL CÓDIGO DE EURICO, in "Estúdios visigóticos" Alvaro d'Ors, Roma Madrid, 1960.

LEX ROMANA VISIGOTHORUM, Gustavus Haenel, Scientia Verlag AAlen, 1962.

FUERO JUZGO en latin y castellano cotejado con los más antiguos y preciosos códices, por la Real Academia Española, Madrid, Ibarra, Impresor de Cámara de S. M., 1815.

MANUAL DE HISTORIA DEL DERECHO ESPAÑOL", Alfonso Garcia Gallo, Madrid, 1975, v. II. (textos) 
Bibliografia

BRAGA DA CRUZ, Guilherme, "História do Direito português" Coimbra, 1955.

BRAVO LIRA, Bernardino, "Formación Del Derecho Occidental" Santiago, Ed. Jur. de Chile, 1970.

BRUNNER - SCHWERIN, "História del Derecho Gemánico", Barcelona, Ed. Labor, 1936.

GIBERT, R., "Elementos formativos del Derecho en Europa: Germánico, Romano, Canónico" Granada, F. Roman, 1975.

SANCHEZ ALBORNOZ, Claudio, "Tradición y derecho visigodo en León y Castilla", in "Investigaciones y documentos sobre las instituciones hispanas", Santiago, Ed. Jurídica de Chile, 1970.

SCOVAZZI, Marco, "Scritti di Storia del Diritto Germanico", Milano, Giuffré, 1975.

ZEUMER, Karl, "Historia de la legislación visigoda", Barcelona, 1944.

AMARAL, Antonio Caetano do, "Sobre o estado civil da Lusitânia desde a entrada dos povos do norte até a dos árabes" in Memórias da Literatura Portuguesa, Lisboa, Academia Real de Ciências de Lisboa, 1796, tomo VI.

BRAGA DA CRUZ, Guilherme, "O problema da personalidade ou da territorialidade da legislação visigótica anteriormente a Rescenvindo" in "História do Direito Português" Coimbra, 1958.

COELHO DA ROCHA, M.A., "Ensaio sobre a História do Governo e da Legislação em Portugal" Coimbra, Imprensa da Universidade, 1872.

VISMARA, G., "El Edictum Theodorici”, in "Estudios Visigóticos", Roma Madrid, 1956

AZEVEDO, L. C., "O Direito de ser citado" S. Paulo, 1980, FIEO - Res. Universitária, pp. 154/167 e 186/201, das quais se reproduziram parte destes comentários. 